\title{
An Abnormality in Sebaceous Function in Phenylketonuria
}

\author{
J. L. BURTON， S. K. GOOLAMALI， SAM SHUSTER
}

British Medical fournal, 1975, 1, 19-20

\section{Summary}

The sebum excretion rate has been found to be increased in female patients with phenylketonuria. This may be related to a depletion of midbrain dopamine and release of the sebotrophic hormone.

\section{Introduction}

We have previously suggested that depletion of midbrain dopamine in Parkinsonism produces an increase in plasma $\beta$-melanocyte stimulating hormone $(\beta-\mathrm{MSH})$ with a consequent seborrhoea (Shuster et al., 1973; Burton et al., 1973 a). This seborrhoea is controlled by levodopa therapy, presumably by repleting midbrain dopamine (Burton et al., $1973 \mathrm{a}$ ). A similar depletion of brain dopamine should also occur in phenylketonuria from the deficiency of phenylalanine hydroxylase, which converts phenylalanine to tyrosine. We therefore measured the sebum excretion rate (S.E.R.) in patients with phenylketonuria.

\section{Patients and Methods}

We studied 10 male and 11 female patients with phenylketonuria aged 13 to 66 years (mean 31). All the patients had severe mental deficiency and one showed signs of mild Parkinsonism. No patient was undergoing hormonal therapy and all received a normal diet. The S.E.R. was measured in every patient by a gravimetric method (Cunliffe and Shuster, 1969) and the results were compared with our control group of 70 male and 93 female subjects aged 10-70 years. The controls were either normal volunteers or patients attending the skin outpatient department for the treatment of localized dermatoses such as warts or tinea pedis.

In six patients the S.E.R. was measured also before and after levodopa therapy ( $1.5 \mathrm{~g}$ daily for six weeks).

\section{Results}

The S.E.R. for each patient was compared with the mean S.E.R. for sex- and age-matched (by decades) control subjects, the difference being expressed as a percentage (see fig.). The mean increase of $83.6 \pm 28.8 \%$ (S.E.M.) in the female patients was highly significant $(P<0.02)$. In the male patients, however, the mean difference of $-4.5 \pm 24.2 \%$ (S.E.M.) did not differ significantly from normal.

The effect of levodopa therapy on the S.E.R. was not consistent and the mean decrease of $0.14 \mu \mathrm{g} / \mathrm{cm}^{2} / \mathrm{min}$. was not significant (see table).

Wellcome Laboratories for Research into Skin Disease, University Department of Dermatology, Newcastle upon Tyne NE1 4LP

J. L. BURTON, M.D., M.R.C.P., Wellcome Research Fellow (present appointment: Senior Lecturer-Consultant in Dermatology, Bristol Royal Infirmary, Bristol BS2 8HW)

S. K. GOOLAMALI, M.R.C.P., Senior Registrar

SAM SHUSTER, PH.D., F.R.C.P., Professor

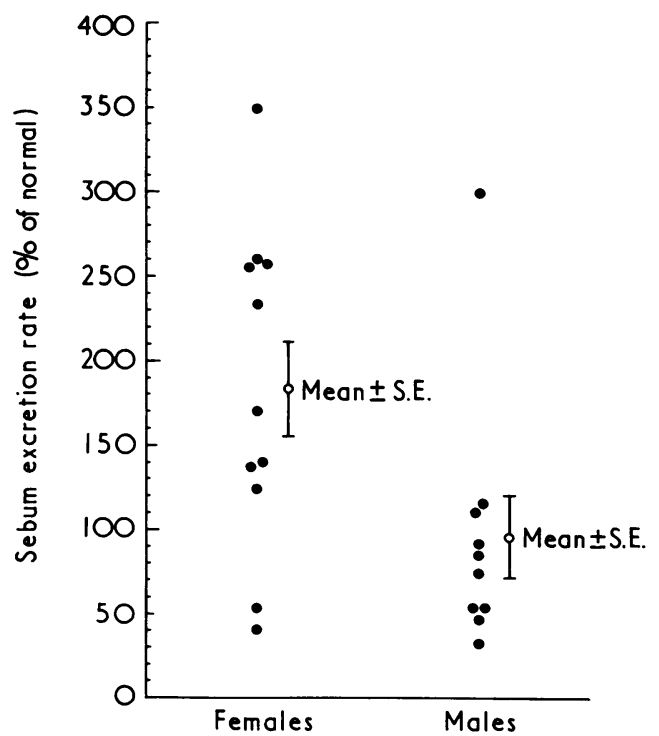

Sebum excretion rate expressed as percentage of normal in male and female patients with phenylketonuria.

Effect of Levodopa on Sebum Excretion Rate in Six Patients

\begin{tabular}{c|c|c|c|c}
\hline Case No. & $\begin{array}{c}\text { Age } \\
\text { (Years) }\end{array}$ & Sex & \multicolumn{2}{|c}{ Sebum Excretion Rate $\left(\mu \mathrm{g} / \mathrm{cm}^{2} / \mathrm{min}\right)$} \\
\hline 1 & 13 & Before Levodopa & After Levodopa \\
\hline 2 & 66 & M. & 0.62 & 0.04 \\
3 & 16 & F. & 0.84 & 1.18 \\
4 & 33 & F. & 0.73 & 0.27 \\
5 & 20 & F. & 0.99 & 0.46 \\
6 & 18 & F. & 0.86 & 0.92 \\
& & & &
\end{tabular}

\section{Discussion}

Our results show that the sebum excretion rate is normal or increased in patients with phenylketonuria. It seems probable that the dry skin previously reported in phenylketonuria (Knox and Hsia, 1957; Paine, 1957) is a manifestation of the eczema which is associated with the disease rather than a change in the greasiness of the skin. Another reason for the discrepancy is that most of the reports of dryness of the skin have come from studies in children, in whom the sebaceous glands are poorly developed. Fleischer and Zeligman (1960) when they examined the skin of 10 adult patients with phenylketonuria found that three had clinical seborrhoea and a fourth had acne, though they concluded that this association was fortuitous.

In phenylketonuria there is a lack of pigment in the skin, hair, and substantia nigra (Crome, 1962) owing to the underlying deficiency of phenylalanine hydroxylase (Hassel and Brunsting, 1959). The same defect could also result in a decrease in brain dopamine (a precursor of melanin) and the excess phenylpyruvic acid found in phenylketonuria might further deplete dopamine by condensation (Robbins, 1968). Depletion of brain dopamine could explain the extrapyramidal signs which occur in phenylketonuria and could also explain the increase in sebum production which we have observed. We have previously suggested that the seborrhoea of Parkinsonism is 
due to increased plasma MSH levels consequent upon dopamine depletion (Shuster et al., 1973). Drugs such as chlorpromazine which deplete or compete with brain dopamine will also induce seborrhoea (Goolamali et al., 1974; Thody and Shuster, 1973; Shuster and Thody, 1974) and an increased release of MSH (Thody and Shuster, 1973), and we expect to find a similar increase in plasma $\mathrm{MSH}$ in patients with phenylketonuria. Recent evidence suggests that $\beta-\mathrm{MSH}$ does not occur naturally in man (Scott and Lowry, 1974) and it is likely that the immunoreactive " $\beta-\mathrm{MSH}$ " we have been measuring (Thody and Plummer, 1973) is related to $\beta$-lipotrophin. This hormone contains the MSH peptide sequence and is strongly sebotrophic (Thody and Shuster, 1971).

Our observation that in patients with phenylketonuria the S.E.R. is increased in women more than in men is difficult to explain but we have similarly noted that the severity of Parkinsonism and degree of seborrhoea is related in women but not in men (Burton et al., 1973 b) even though the plasma immunoreactive " $\beta-M S H$ " is increased in both sexes (Shuster et al., 1973). Not too much importance should be attached to our failure to find a consistent decrease in S.E.R. after levodopa because only a few patients were given the drug and not all of these had seborrhoea and it has been shown that the decrease in S.E.R. after levodopa in Parkinsonism is related to the !nitial seborrhoea. The effect of levodopa requires further study both to establish the effect on the S.E.R. and because of its possible use in the management of the disease.

We thank the psychiatrists at the Prudhoe and Monkton Hospital, Northumberland, the Northgate and District Hospital, Morpeth, and the Royal Albert Hospital, Lancaster, for permission to study their patients. Thanks are also due to the Medical Research Council, the Wellcome Trust, and the North of England Cancer Campaign for grants.

\section{References}

Burton, J. L., Cartlidge, M., and Shuster, S. (1973 a). British fournal of Dermatology, 88, 475

Burton, J. L., et al. (1973 b). British fournal of Dermatology, 88, 263.
Crome, L. (1962), fournal of Neurology, Neurosurgery, and Psychiatry, 25, 149. Cunliffe, W. J., and Shuster, S. (1969). British fournal of Dermatology, 81,

Fleischer, T. L., and Zeligman, I. (1960). Archives of Dermatology, 81, 898. Goolamali, S. K., et al. (1974), In preparation.

Hassel, C. W., and Brunsting, L. A. (1959). Archives of Dermatology, 79, 458. Knox, W. E., and Hsia, D. Y. Y. (1957). American fournal of Medicine, 22, 687.

Paine, R. S. (1957). Pediatrics, 20, 290

Robbins, J. (1968). Clinical Research, 16, 554

Scott, A. P., and Lowry, P. J. (1974). Fourney of Biochemistry, 139, 593. Shuster, S., and Thody, A. J. (1974). Fournal of Investigative Dermatology, 62,172

Shuster, S., et al. (1973). Lancet, 1, 463.

Thody, A. J., and Plummer, N. A. (1973). Fournal of Endocrinology, 58, 263. Thody, A. J., and Shuster, S. (1971). Fournal of Endocrinology, 50, 533 Thody, A. J., and Shuster, S. (1973). Fournal of Endocrinology, 58, XXV.

\section{MEDICAL MEMORANDA}

\section{Ventricular Septal Defect in a Battered Child}

\section{ALAN REES, JOHN SYMONS, MICHAEL JOSEPH, CHRISTOPHER LINCOLN}

British Medical fournal, 1975, 1, 20

Manifestations of deliberate injury to children, the so-called battered babies, have included descriptions of damage to almost every organ since the original observations of Caffey (1946). A history of repeated trauma in the home caused by one of the immediate family seems to us more important in making this diagnosis than the age of the victim. The case presented here shows clear evidence of a traumatic ventricular septal defect (V.S.D.). Reviews of the literature on this condition (Pollock et al., 1952; Rubinstein and Levison, 1961; Rosenthal et al., 1970; Moraes et al., 1973) show the numbers to be small, children to be rarely involved, and deliberate trauma to be uncommon.

\section{Case History}

A 5-year-old girl was well until 14 days before admission to hospital. She had been under hospital observation for the first eight months of life because of low birth weight and under close review by her family doctor since then because of poor social circumstances. No heart murmur had ever been heard; she had been fit and active. Two weeks after an assault by her stepfather

Paediatric Department, Brompton Hospital, London SW3 6HP ALAN REES, F.R.C.s., Senior Surgical Registrar JOHN SYMONS, M.R.C.P., Senior Medical Registrar MICHAEL JOSEPH, F.R.C.P., Consultant Paediatrician CHRISTOPHER LINCOLN, F.R.c.s., Consultant Cardiac Surgeon during which she was kicked in the chest, however, the family doctor found her to be in cardiac failure with a loud systolic murmur. She was referred to the local general hospital and then transferred to the paediatric cardiac unit at this hospital for investigation.

On admission she looked ill and had multiple bruises, though there were none on her chest or abdomen. There was a sinus tachycardia $(160 / \mathrm{min})$. Blood pressure was $75 / 40 \mathrm{~mm} \mathrm{Hg}$ and the jugular venous pressure was raised. The liver was palpable $4 \mathrm{~cm}$ below the costal margin and there was slight oedema of the feet and ankles. A systolic thrill was felt over the anterior chest and a grade 5/6 pansystolic murmur was heard maximally at the left sternal edge at the fourth left intercostal space. The first and second sounds were normal and the third sound was present. There was tachypnoea $(60 / \mathrm{min})$ and fine crepitations at both lung bases.

Investigations.-Haemoglobin $10.3 \mathrm{~g} / 100 \mathrm{ml}$; packed cell volume $34 \%$; mean corpusoular haemoglobin concentration $30 \%$; white cell count $8,500 / \mathrm{mm}^{3}$ (normal differential); urea and electrolytes normal. $X$-ray examination showed an enlarged heart with perihilar shadowing suggestive of pulmonary oedema. The left atrium was not enlarged. E.C.G. showed sinus rhythm and a mean frontal $\mathrm{QRS}$ axis of $+45^{\circ}$. There was a $3-\mathrm{mm} P$ wave in lead II, indicating right atrial hypertrophy (Liebman, 1968). Otherwise the tracing was within normal limits. Echocardiography showed a left ventrioular output estimated at $12 \mathrm{l} . / \mathrm{min} / \mathrm{m}^{2}$. At cardiac catheterization a large V.S.D. was shown by oximetry with a pulmonary to systemic flow ratio of $8 \cdot 1$. Peak ventricular systolic pressures were left $75 \mathrm{~mm} \mathrm{Hg}$, right $32 \mathrm{~mm} \mathrm{Hg}$. Left ventricular cineangiography showed no mitral incompetence but a defect low in the ventrioular septum.

Management.-Operation was deferred for eight weeks from the time of the injury to allow the margins to fibrose. The cardiac failure was controlled with digoxin and diuretics and the radiological signs of pulmonary oedema cleared, though pulmonary plethora remained with cardiac enlargement. The child was breathless on moderate exertion but otherwise appeared well and active. The defect was closed using cardiopulmonary bypass. There was an aneurysmal area about $2 \mathrm{~cm}$ by $1.5 \mathrm{~cm}$ in the apex of the right ventricle (fig. 1). On incising this the defect was seen in the apex of the muscular septum (fig. 2). It was relatively large, $1.5 \mathrm{~cm}$ in diameter, with mangins composed of firm fibrous tissue. It communicated with a false chamber in the apex of the right ventricle formed partly by the aneurysm and, in a cephalad direction, by 